\title{
A Clearinghouse Concept for Distribution-Level Flexibility Services
}

\author{
Heussen, Kai; Bondy, Daniel Esteban Morales; Hu, Junjie; Gehrke, Oliver; Hansen, Lars Henrik
}

Published in:

Proceedings of IEEE Innovative Grid Technologies Europe 2013

Link to article, DOI:

10.1109/ISGTEurope.2013.6695483

Publication date:

2013

Link back to DTU Orbit

Citation $(A P A)$ :

Heussen, K., Bondy, D. E. M., Hu, J., Gehrke, O., \& Hansen, L. H. (2013). A Clearinghouse Concept for Distribution-Level Flexibility Services. In Proceedings of IEEE Innovative Grid Technologies Europe 2013 IEEE. https://doi.org/10.1109/ISGTEurope.2013.6695483

\section{General rights}

Copyright and moral rights for the publications made accessible in the public portal are retained by the authors and/or other copyright owners and it is a condition of accessing publications that users recognise and abide by the legal requirements associated with these rights.

- Users may download and print one copy of any publication from the public portal for the purpose of private study or research.

- You may not further distribute the material or use it for any profit-making activity or commercial gain

- You may freely distribute the URL identifying the publication in the public portal

If you believe that this document breaches copyright please contact us providing details, and we will remove access to the work immediately and investigate your claim. 


\section{A Clearinghouse Concept for Distribution-Level Flexibility Services}

\author{
Kai Heussen, Daniel Esteban Morales Bondy, Junjie Hu, Oliver Gehrke \\ Department of Electrical Engineering \\ Technical University of Denmark \\ Email: \{kh, bondy, junhu, olge $\}$ elektro.dtu.dk
}

\author{
Lars Henrik Hansen \\ DONG Energy \\ Gentofte, Denmark \\ Email: larha@dongenergy.dk
}

\begin{abstract}
Flexibility resources on the demand side are anticipated to become a valuable asset for balancing renewable energy fluctuation as well as for reducing investment needs in distribution grids. To harvest this flexibility for distribution grids, flexibility services need to be defined that can be integrated with distribution grid operation and that provide a benefit that can be traded off against other grid investments. Two key challenges are here that the identification of useful services is still ongoing and that the transaction cost for the individually small contributions from the demand side could be prohibitive. This paper introduces a flexibility clearinghouse (FLECH) concept and isolates FLECH key functionality: to facilitate flexibility services in distribution grids by streamlining the relevant business interactions while keeping technical specifications open.
\end{abstract}

\section{INTRODUCTION}

Procuring system services from small distributed energy resources (DER), including flexible demand, has become a focus of research and field trials in recent years. The capability of managing DER via aggregators, to participate in bulk power markets as well as to provide system (ancillary) services has achieved much progress. Yet the provision of such services at distribution level has not seen the same development, either because they are simply uneconomic or possibly because marketbased approaches are not easily introduced to distribution system operations.

\section{A. Demand Response and Distribution Grid Planning and Operation}

Two new drivers for increased grid demand are: 1) the development of renewables, in particular solar photovoltaic installations, and 2) the introduction of controllable and likely price responsive power consuming/producing units, including heat pumps and electric vehicles. These new units may cause grid issues such as voltage violations, reverse power flows, or thermal overloading. Such grid issues force distribution system operators (DSOs) to consider costly reinforcements while the effective grid utilization may actually be decreasing due to reduced diversity amongst the price responsive loads. Distribution grid planning and operation are conventionally focussed on planning and maintenance and are only slowly adopting "smart" approaches involving automation. The smart grid is suggested to enable better infrastructure utilization and the accommodation of additional generation and demand. One modern approach to increasing the effective hosting capacity of distribution grids is to improve situational awareness for grid operators and planners through better feedback about the operating state [1].

Another approach is a better utilisation of demand side flexibility through new demand response programs, or 'flexibility services' [2]. Aggregating and controlling DER for commercial purposes is a field for new actors where technological and business innovation are essential for development. This development will either be facilitated or hampered by regulatory choices. The need for a regulatory framework for commercial flexibility services at the distribution level has been recognized, e.g. by the standardization mandate M490 and with the introduction of the traffic light concept [3], and is under development.

The introduction of new flexibility services at distribution level is thus a current and relevant concern, while, clearly, both the service definitions and the potential market-based coordination of such services are still largely open problems.

\section{B. Congestion Management in Distribution Grids}

At transmission level, congestion constraints are a common tool for reflecting transmission limitations toward market mechanisms, e.g. when interconnecting market areas. Congestion occurs when scheduled energy flows exceed the available transmission capacity [4]; congestion management is then the allocation of transfer capacity according to economic principles. Based on this definition, congestion can also be defined for distribution networks [5] as a coordination strategy reflecting operational constraints on market terms. A study in [5] analyzed three kinds of market mechanisms for alleviating congestion. In [6]-[8], prices are used to coordinate between DSO, aggregators and DER owners to achieve an optimal allocation, and in [9] different grid tariffs are discussed.

A simplification common in the distribution congestion literature [5]-[9] is to focus on 'bottleneck' constraints on a summation of power flows. This constraint can be interpreted as transformer current limit - for which there exists a business case on deferring grid investments. However, a DSO's actual decision drivers and investment alternatives are often more varied and complex than the ones considered here, and regulatory requirements often inhibit the application of congestion constraints in distribution grids. 
To achieve an incremental adoption and a better match of flexibility services with DSO regulations and procedures, DSOs should be enabled to request flexibility services adapted to actual practices of distribution system planners and to needs of flexibility service providers.

This paper introduces a concept which respects the practical requirements of a technically advancing DSO while opening the efficiency potential of market-based congestion management: the Flexibility Clearinghouse (FLECH). Following three key design principles, 1) to minimize transaction cost for DSO flexibility services; 2) to allow for further technical specifications of DSO services; and 3) to focus on business transactions and do not interfere with with distribution operations, this concept has been developed and implemented within the Danish research and innovation project iPower: www.iPower-net.dk.

\section{FleXibility SERVICES FOR Distribution OPERATION}

This Section defines the concept of a Flexibility Service, provides examples, and a framework for analysis.

\section{A. Definition of a Flexiblity Service}

Many DER units have the capability of altering their generation/consumption pattern with limited impact on their primary energy service. This capability is further referred to as DER flexibility. Flexibility can be provided to a DSO through a new dedicated ancillary services market to which entities representing DER, here Aggregators, can submit bids. The products on this market are called flexibility services and include a detailed specification of the service procurement, activation, delivery, validation and settlement. These services include two generic types: (A) fully scheduled services which oblige the aggregator to behave as contracted without DSO intervention, and as well as (B) reserve services which entail a reserve or availability combined with a need-based activation by the DSO.

\section{B. DSO Flexibility Service Examples}

An analysis of relevant issues in the distribution system, reported in [2], identifies four key needs that could be fulfilled by flexibility services: response to foreseen and unexpected overloading, fast response to resolve N-1 situations, support in case of voltage limit violations (power quality), and support with respect to reactive power exchange with the transmission grid.

The same report, [2], suggests seven potential flexibility services to support the above needs. This paper will focus on those five services which offer flexibility via active power management:

1) PowerCut Planned: Used for handling predictable peak load for periodically daily issues in advance.

2) PowerCut Urgent: Used for handling peak loads on an event basis.

3) Power Reserve: Used when the system is operating in the reserve band of the feeder, and a fault in the system would require the utilization of the reserve band.
4) PowerCap: Activated upon request to ensure that the capacity limits specified by the DSO are not violated.

5) PowerMax: Same function as PowerCap, but activated through a planned schedule.

These services address the first two needs mentioned above, i.e. response to overloading and to N-1 situations. Notably, they include both fully scheduled products, i.e. (1) and (5), as well as reserve products, (2)-(4). As stipulated in [2], these service definitions are expected to be among the first ones accepted by DSOs. However, they do not constitute an exhaustive list of potential services.

\section{A Framework for Analyzing Flexibility Services}

In [5] an analysis framework of four stages for has been introduced: 1) Offline Planning, 2) Online Scheduling, 3) Realtime Operation, 4) Offline Settlement.

The framework is suited to identify alignement of technical and market functions across all participating actors. Key operations for each stage are listed in Table I.

TABLE I

STAGES OF SERVICE PROVISION AND ASSOCIATED FUNCTIONS

\begin{tabular}{|c|c|c|}
\hline Stage & Market function & Technical function \\
\hline Offline Planning & $\begin{array}{l}\text { Contract specification } \\
\text { and cost allocation }\end{array}$ & $\begin{array}{l}\text { Grid planning and ser- } \\
\text { vice specification }\end{array}$ \\
\hline Online Scheduling & $\begin{array}{l}\text { Contracting and re- } \\
\text { source allocation }\end{array}$ & $\begin{array}{l}\text { Scheduling and reser- } \\
\text { vation }\end{array}$ \\
\hline Real-time Operation & Contractual fulfillment & $\begin{array}{l}\text { Plan execution and ac- } \\
\text { tivation/response }\end{array}$ \\
\hline Offline Settlement & Financial settlement & Service validation \\
\hline
\end{tabular}

The stages and the separation of market and technical operations define a framework suited for the analysis of flexibility services and isolation of FLECH functionality.

\section{The FleXibility Clearinghouse ConCePt}

As described in [2], the FLECH is meant to facilitate DSOs to announce services and aggregators to bid upon. Here, the stakeholder setting and FLECH core functions are identified.

\section{A. Stakeholder Roles and Need for a Flexiblity Clearinghouse}

Demand for system services from DER units exist all the way down to the low voltage grid. We identify associated interests with respect to the following conventional stakeholders:

- Transmission System Operator (TSO)

- Distribution System Operators (DSOs)

- Balance Responsible Parties (BRP)

New stakeholders in the context of DER services include:

- DER owners

- Aggregators

All stakeholders have interests of their own that require alignment to enable successful delivery of flexibility of flexibility services to a DSO. The DER owner is interested in offering flexibility which does not negatively influence the primary function of the unit. This flexibility will be defined in contracts between the DER owner and an Aggregator. 


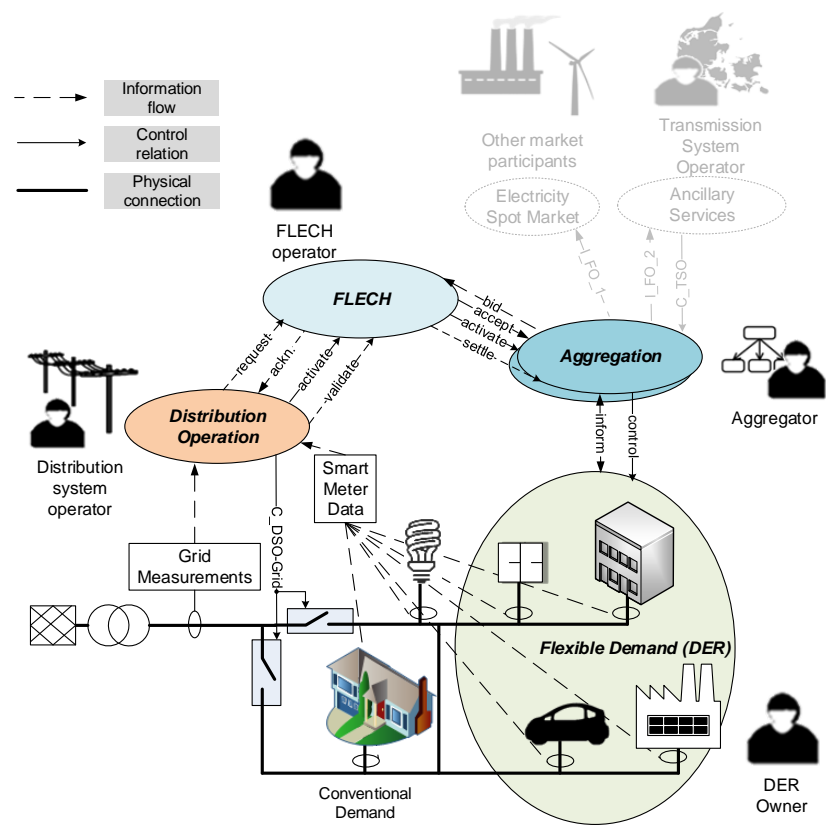

Fig. 1. Schematic overview of the considered actors and their roles in relation to the FLECH.

Depending on the capabilities of a particular DER unit, it may be able to offer system services to more than one interested party. For example, a controlled decrease in consumption could either be part of a frequency control service offered to a TSO, or it may be offered to a DSO for peak shaving. In any case, the invocation of the service would impact both grid domains, and the interests of TSO and DSO could conflict. In the present electricity market regulation, larger DER units interact with a TSO through a BRP. The business model of a BRP adds another set of interests which do not automatically align with the requirements of grid operation.

Two present ways of addressing flexiblity services are grid codes and bilateral contracts. Grid codes are primarily suited to define absolute limits of operation. They have to be rigid as their scope is universal to all grid connected devices. The creation and updating of grid codes is a slow process which is not very innovation friendly and does not imply any remuneration. Individually negotiated bilateral contracts, on the other hand, imply a high transaction cost, which makes them unsuitable for services with small economic margins.

This setting illustrates the need for a service-independent and open platform for the arbitration of interests between the stakeholders involved in delivering a power system service from flexible DER units. The scope of this platform should be limited to providing an infrastructure on top of which the business logic of present and future services can be defined.

\section{B. Functions of FLECH}

A clearinghouse is a safeguard for a marketplace, ensuring the secure fulfilment of a business transaction. FLECH provides the platform for such transactions with respect to smart services in the interest of a distribution system operator.

The FLECH concept is realized as a service-oriented platform that facilitates the business process of specifying, contracting, delivery and settlement of DER flexibility services. It requires involvement of a software provider. For operation, a new neutral stakeholder, similar to the role of a market operator for the bulk electricity markets, should be introduced.

The capability of FLECH will evolve with the development of distribution level markets. Initially, market clearing can be performed by the DSO. The FLECH functionality would mainly consist of bookkeeping and communication/broadcasting functions. In the future, when market mechanisms are more stable and services well-defined, market clearing would be implemented on the FLECH platform. Another optional functionality is a coordination role in the scheduling phase. None of the specified services in [2] require such functionality as it is allocated to DSO and Aggregators internally. For future congestion management strategies, such as reported in [5], online coordination of several aggregators would theoretically be more economically efficient.

During operation, two alternative service types - reserve and scheduled - need to be distinguished. To avoid technical real-time requirements for FLECH, the activation of reserve services should be sent directly to the respective aggregator, while FLECH assumes a pure bookkeeping role.

Finally, FLECH supports service validation and settlement. As all records of activations are available, FLECH can match bids and fulfillment and calculate the final settlement.

\section{FLECH INTERACTIONS}

The FLECH functionality outlined above aims to facilitate interactions between DSO and flexiblity service providers; this section identifies the required interactions and isolates the common message exchange requirements.

\section{A. Flexibility Service Mapping}

The framework introduced in Section II-C is used to map out the FLECH interactions for the candidate flexiblity services summarized in Section II-B. Here, two services, PowerCut Urgent and PowerMax, are chosen as representative cases and their mapping is summarized in Tables II and III.

TABLE II

POWERCUT URGENT

\begin{tabular}{lll}
\hline Stage & Market function & Technical function \\
\hline Offline Planning & $\begin{array}{l}\text { Specification and an- } \\
\text { nouncement of reserve } \\
\text { contract } \\
\text { (optional: call for short } \\
\text { term bids to activation } \\
\text { market) }\end{array}$ & $\begin{array}{l}\text { DSO: identify location } \\
\text { and volume of reserve } \\
\text { need }\end{array}$ \\
$\begin{array}{l}\text { DSO: Anticipate 'ur- } \\
\text { gent activation need } \\
\text { time }\end{array}$ \\
Real-time Operation & - & $\begin{array}{l}\text { DSO: Activation } \\
\text { signal; DER respond }\end{array}$ \\
within 15min \\
Offline Settlement & $\begin{array}{l}\text { Payment per activa- } \\
\text { Recording and valida- } \\
\text { tion. Failure to de- } \\
\text { liver 4 times termi- } \\
\text { nates contract. }\end{array}$ & \\
& nal and response sig- \\
\hline
\end{tabular}




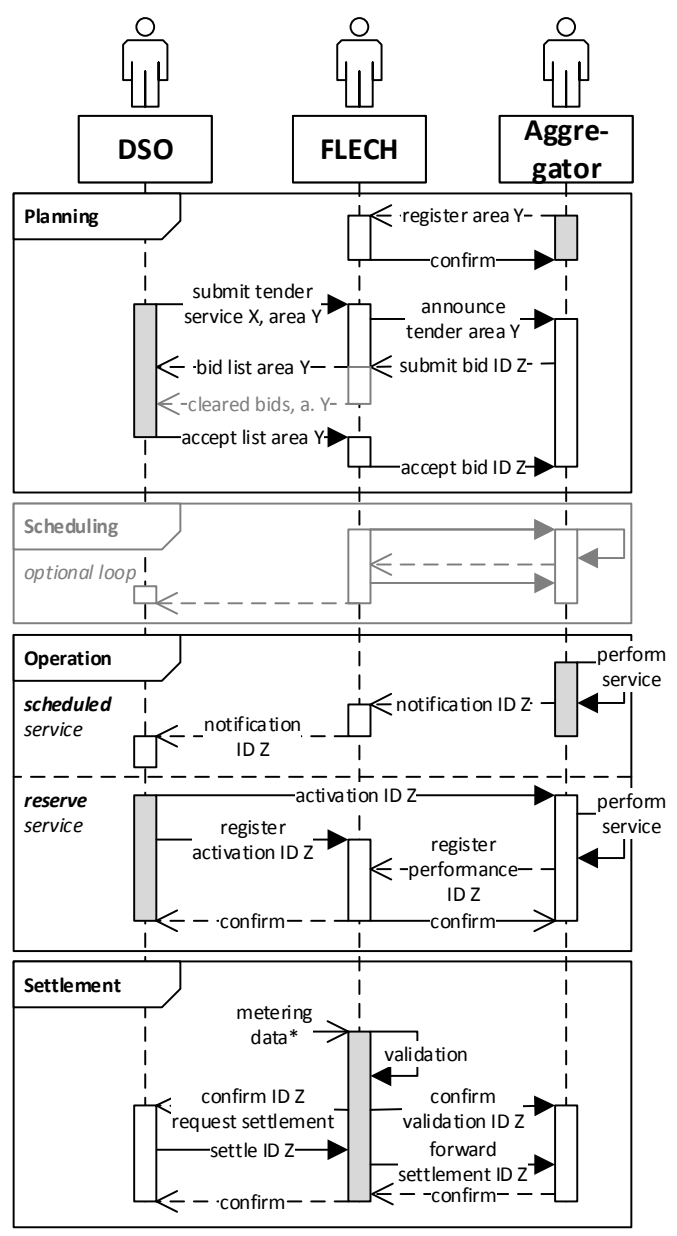

Fig. 2. Sequence diagram for FLECH communication

TABLE III

POWERMAX

\begin{tabular}{|c|c|c|}
\hline Stage & Market function & Technical function \\
\hline Offline Planning & $\begin{array}{l}\text { Announce service re- } \\
\text { quest }\end{array}$ & $\begin{array}{l}\text { Identify activation } \\
\text { location, periods and } \\
\text { volume }\end{array}$ \\
\hline Online Scheduling & (optional coordination) & $\begin{array}{l}\text { (DER and Aggregator: } \\
\text { prediction) }\end{array}$ \\
\hline Real-time Operation & - & $\begin{array}{l}\text { DSO: monitoring } \\
\text { only; } \\
\text { coordinates DER }\end{array}$ \\
\hline Offline Settlement & $\begin{array}{l}\text { Payment defined in the } \\
\text { contract. Failure to de- } \\
\text { liver } 4 \text { times termi- } \\
\text { nates contract }\end{array}$ & $\begin{array}{l}\text { Recording and valida- } \\
\text { tion of activation sig- } \\
\text { nal and response }\end{array}$ \\
\hline
\end{tabular}

The following conclusions can be drawn from the analysis: At the planning stage, tender announcement and reserve agreements with a long lead-time are arranged, e.g. 2 - 6 months before activation. The scheduling phase is optional, yet valuable in a competitive setting: due to short lead time (e.g 1 - 24h ahead) bid prices would improve due to reduced uncertainty. At the operation stage, the services can be differentiated into reserve and scheduled services. For scheduled services a simple notification of activation will be performed. For reserve services, the DSO will send an activation signal directly to the aggregator. FLECH must be notified if the activation is executed. The notifications are used for settlement. With regards to offline settlement, FLECH will be the responsible for coordinating validation, consolidating the judgment from different actors.

\section{B. Generic FLECH Messages}

The FLECH key interfaces are to DSO and Aggregator. The sequence diagram in Figure 2 summarizes the essential message flow, grouped by stage. Focussing on the transactional, administrative, aspects of service provision, the key interactions are common to all services considered, with two exeptions: the scheduling stage would depend on the respective service and market clearing model, and in the operation stage, separate sequences are defined for scheduled and reserve services. The adoption of new services to the a first FLECH design will therefore come at a small incremental cost.

\section{CASE Study}

This case study illustrates the application of the PowerMax service by a DSO in case of an anticipated low voltage transformer overload. Consider the following scenario:

(A) 70 household consumers are connected to a $10 / 0.4 \mathrm{kV}$ transformer $\mathrm{T} 1$, each with connection capacity of approximately $7 k W$; an electric vehicle (EV) with up to $3.7 k W$ charging capacity, [10], is associated with 14 of the households.

(B) Aggregators managing controllable consumption in this grid area are two EV fleet operators, FO1 and FO2. FO1 operates $5 \mathrm{EVs}$ and FO2 $9 \mathrm{EVs}$, corresponding to $18.5 \mathrm{~kW}$ and $33.3 \mathrm{~kW}$ charging capacity, respectively.

(C) Based on historical data and specific load models, the DSO anticipates that the $175 \mathrm{~kW}$ limit (corresponding to $70 \%$ of the maximum $250 \mathrm{~kW}$ ) of transformer T1, may be exceeded by $37.8 \mathrm{~kW}$ on weekdays between $4: 30 \mathrm{pm}$ and $8: 00 \mathrm{pm}$ during the months of December, January and February, mainly caused by additional EV charging loads; the corresponding load profile is illustrated in Figure 3.

(D) The DSO has the option to reinforce the transformer or to acquire a flexibility service. An economical evaluation suggests that flexibility services could postpone reinforcement and thus are an attractive option. Due to the characteristics of EV loads, the PowerMax service is chosen as most viable.

To prepare the FLECH tender, the DSO identifies its needs: having $14 \mathrm{EVs}$ with flexible consumption in the area charging at maximum rate, the peak load of the EVs is $51.8 \mathrm{~kW}$ under current Danish regulations, the only capacity limit is the physical connection capacity. The DSO thus needs to reduce, for the given time window, this maximum capacity limit to $14 k W$, i.e. the total capacity of the two aggregators should be reduced by $37.8 \mathrm{~kW}$. With PowerMax, the DSO therefore requests a reduction against documented connection capacity of the aggregators in the area. Apart from announcing the quantity to be reduced, the DSO includes a 'recommended' rate in order to initiate price discovery. 

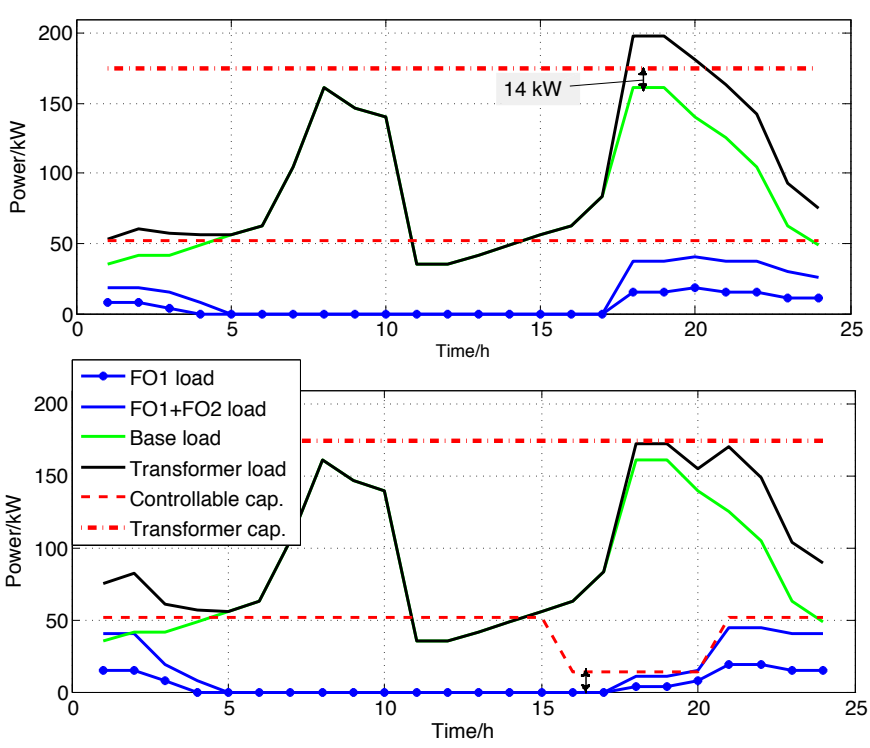

Fig. 3. Expected load profiles for days with anticipated feeder overload. Top: Expected profile before PowerMax tender. Bottom: Expected profile after PowerMax tender.

In this scenario, FLECH facilitates the tender and transactions associated with the service provision. The individual steps are related to Figure 2. At the planning stage, the DSO submits the following service tender to FLECH:

PowerMax:

CAPACITY REDUCTION [AREA T1] : $37.8 \mathrm{~kW}$

TIME 4:30pm TO 8:00pm ON weekdays

PERIOD 01 Dec 2014 TO 28 Feb 2015

RECOMMENDED RATE $500 \mathrm{EUR} / \mathrm{kW}$

This tender is then announced by FLECH to all aggregators registered for T1. The aggregators bid into the FLECH:

AggID [BidID]: reduction FROM capacity AT rate flex?

FO1 [FO1B1] : $12.3 k W$ FROM $14.8 k W$ AT 500 EUR/kW FULL

FO2 [FO2B1] : $12.3 k W$ FROM $14.8 k W$ AT 700 EUR/kW FULL

FO2 [FO2B2] : $15.4 k W$ FROM $18.5 k W 1000 \mathrm{EUR} / \mathrm{kW}$ FLEX

Note that FO1 did not bid with all of its resources, effectively only using 4 out of 5 cars, and that the second bid by FO2 is FLEX bid, i.e. it does not need to be accepted entirely. After gate closure their bids are forwarded to the DSO which evaluates the offers and decides to accept the following bids: BidID: FO1B1, FO2B1, FO2B2*90\% AT 1000 EUR/kW

This leads to an effective capacity reduction of $38.5 \mathrm{~kW}$ which fulfills the required $37.8 \mathrm{~kW}$. The prices of this case study are completely fictitious and not anchored in real costs.

As the PowerMax service includes a schedule, aggregators determine their commitment internally and no interaction is required at the online scheduling stage. At the operation stage FLECH collects the activation notifications which are passed on to the DSO to verify the performance. At the settlement stage, the Metering Responsible submits metering data to FLECH and FLECH validates the performance. The settlement transaction is facilitated by FLECH.

\section{CONCLUSION}

This paper presented a clearinghouse concept for facilitating ancillary services at the DSO level. With the emergence of new players in DSO ancillary service markets, it is foreseen that such a mechanism will be needed to minimize transaction costs. In contrast to other contributions on distribution congestion mitigation, the FLECH adapts to the actual DSO needs and is not tied to a specific aggregator architecture

Two representative flexibility services have been chosen to identify the FLECH requirements. By separating market and technical aspects of the services, it is possible to isolate the need for a pure market facilitator, which either facilitates bilateral contracts or operates a market-clearing facility.

The role of FLECH and its interactions with stakeholders of the distribution flexibility service market have been described. A case study has been presented showing how FLECH is envisioned to work in a concrete scenario.

Several important aspects of flexiblity services have been out of the scope of this paper and will be addressed in future work: (A) A flexiblity service requires the formulation of a 'baseline'. This baseline at transmission level is based on the energy markets, but there is no such formal baseline at the distribution level for DER. (B) The activation of flexibility services may potentially cause an imbalance cost. It is not clear to which actor this cost should be allocated. $(C)$ The aggregator is assumed to be an independent entitiy representing the DER towards FLECH and the DSO. This assumption is currently not backed up by regulation, partly because of the imbalance issue noted in point (B).

\section{REFERENCES}

[1] P. VINTER and H. KNUDSEN, "Using continuous state estimation in grid planning," in In Proceedings of the 20th International Conference on Electricity Distribution Pragu, 8-11 June 2009.

[2] N. C. Nordentoft, Y. Ding, L. H. Hansen, P. D. Cajar, P. Brath, H. W. Bindner, and C. Zhang, "Development of a dso-market on flexibility services," iPower, http://ipower-net.dk/Publications.aspx, Tech. Rep., 2013.

[3] Smart grid use case management process. CEN-CENELEC-ETSI Smart Grid Coordination Group - Sustainable Processes.

[4] M. Shahidehpour and Y. Wang, Communication and control in electric power systems: applications of parallel and distributed processing. Wiley-IEEE Press, 2004.

[5] P. Bach Andersen, J. Hu, and K. Heussen, "Coordination strategies for distribution grid congestion management in a multi-actor, multi-objective setting," in ISGT Europe (Berlin). IEEE, 2012, pp. 1-8.

[6] B. Biegel, P. Andersen, J. Stoustrup, and J. Bendtsen, "Congestion management in a smart grid via shadow prices," in Proc. 8th IFAC Symp. on Power Plant and Power System Control, Toulouse, 2012.

[7] E. L. Karfopoulos and N. D. Hatziargyriou, "A multi-agent system for controlled charging of a large population of electric vehicles," IEEE Transactions on Power Systems, 2012.

[8] J. Greunsven, E. Veldman, P. Nguyen, J. Slootweg, and I. Kamphuis, "Capacity management within a multi-agent market-based active distribution network," in Innovative Smart Grid Technologies (ISGT Europe), 2012 3rd IEEE PES International Conference and Exhibition on. IEEE, 2012, pp. 1-8.

[9] L. H. Rasmussen, C. Bang, and M. Togeby, "Managing congestion in distribution grids-market design consideration," Ea Energy Analyses, Tech. Rep., 2012.

[10] F. Marra, G. Y. Yang, C. Traholt, E. Larsen, C. Rasmussen, and S. You, "Demand profile study of battery electric vehicle under different charging options," in PES General Meeting, 2012 IEEE, 2012, pp. 1-7. 